\title{
Assertive Classroom Management: How Does it Mould Students' Perceptions of Classroom Activities and Goal Orientations?
}

\author{
Zahra Ahmadi Yazdi \\ Imam Reza International University, Mashhad, Iran
}

Afsaneh Ghanizadeh

Imam Reza International University, Mashhad, Iran, ghanizadeafsane@yahoo.com, a.ghanizadeh@imamreza.ac.ir

Vahid Mousavi

Imam Reza International University, Mashhad, Iran

\begin{abstract}
This study assessed the impact of teachers' assertive classroom management on the students' perception of classroom activities and their goal orientations. It adopted a mixed method approach (QUANTITATIVE $\rightarrow$ qualitative.). The population consisted of about 590 consisted of Iranian university and institute students out of which 147 were sampled. They were administered three questionnaires and five were interviewed. To gauge teachers' assertive classroom management, we utilized a questionnaire developed by Shawer (2010). It includes 37 items measuring four components of teacher's assertive classroom management (organization, teaching strategies, teacher-student relationship strategies, teacher's punishment- reward strategies). To assess students' perceptions of classroom activities, a scale designed and validated by Gentry and Gable (2001) was utilized. It comprises 31 items and consists of 4 components (interest, challenge, choice, and joy). The students' goal orientations were measured via 'achievement goal orientation inventory' designed by Midgley, et al. (1998). The inventory comprised three subscales (mastery-approach, performance-approach, performance-avoidance approach) and a total of 18 items. In the quantitative phase, the results demonstrated that teachers' assertive classroom management strategies predicted students' perceptions of classroom activities exhibiting the highest influence on challenge and interest respectively. Mastery goal was influenced by teacher assertive classroom management strategies. The results of the quantitative phase confirmed the findings of the quantitative phase.
\end{abstract}

Keywords: classroom management, goal orientations, mixed- methods approach, students' perception of classroom activities

\section{INTRODUCTION}

One major aspect of the classroom atmosphere that has fallen under the control of the teacher is that of classroom management and discipline. Teachers do not choose their classrooms. However, they do have control over the kind of classroom atmosphere they construct with their students and the kinds of instructional practices they utilize. Teachers who are successful in establishing effective classroom atmosphere make more time for learning, involve more students, and help students to become selfmanaging (Mucherah \& Frazier, 2013). A positive learning environment must be established and maintained throughout the year. One of the best way's teachers achieve this goal is by having a good classroom management.

Citation: Yazdi, Z. A., Ghanizadeh, A., \& Mousavi, V. (2019). Assertive Classroom Management: How Does it Mould Students' Perceptions of Classroom Activities and Goal Orientations? Anatolian Journal of Education, 4(2), 39-52. https://doi.org/10.29333/aje.2019.425a 
Teachers of all types often try to keep their classrooms free from disorder. To do so, they need to manage the class and correct the learners' behavior in such a fervent way that encourages, motivates, and retains positive behavior. Classroom management contains establishing rules to organize the class, to prepare materials and activities, and to explain instructions and consequences of acting up. Wong and Rosemary (2001) defined classroom management as "all the things that a teacher does to arrange students, space, time and materials so that teaching lessens and student learning can take place" (p. $84)$.

Furthermore, as Wong and Rosemary (2001) noted, all the practices and procedures that a teacher applies to have a good classroom environment in which teaching and learning can take place is related to classroom management. To achieve this, teachers need to apply a set of strategies to organize space, time, and materials. The teacher's classroom management affects some aspects of student's behaviors such as perceptions and beliefs, motivation, achievement goals, and academic achievement. In this study, it is presumed that it would impact on students' perceptions of classroom activities and their achievement goals.

The procedure by which we receive and interpret information from the world around us is called Perception. The world around us is made of different levels and kinds of physical energy. Our knowledge of the world comes through our sense organs, which respond to these energies. Many factors influence what and how we perceive our environment. Teachers' and students' views about the perceptions of classroom activities are important areas to consider when designing effective learning experiences (Ghanizadeh \& Jahedizadeh, 2015). The students' perceptions consist of four main parts; interest, choice, challenge, and joy. Each of these tenets plays an important role in perceptions students get from their classroom environment (Ghanizadeh \& Jahedizadeh, 2015).

Sullivan (2007) contended that teacher support, peer support, and teachers' interpersonal styles shape the students' perception of classroom environment; and these perceptions strongly predict perceptions of competence and instrumentality of the goal orientations as well as the content. To empirically examine the Hardré and Sullivan's (2007) contention, the present study focuses on the hypothesized role of teachers' management skills in students' perceptions of classroom environment as well as their perceptions of educational goals, i.e., achievement goal orientations.

How students move towards a particular goal is goal orientation. It is the main organizing construct in goal theory. For example, a student may strive to do well in a given class. The goal is to do well, but the reason for holding that goal may differ. For one student, doing well may show that his or her purpose is to master the material, while for another it may mean he or she wants to do better than other students, and for a third it might mean determination to get high grades.

In this way, Elliot and Harackiewic (1996) offered a three-factor model of achievement goals consisting of mastery, performance-approach, and performance-avoidance goals. A performanceapproach goal was defined as trying to demonstrate competence relative to others, while performance-avoidance goal was defined as trying to avoid incompetence relative to others. This distinction was readily embraced by educational scholars on the grounds that it contributed to a better account for the pattern of opposing relationships between performance goals and diverse adaptive and maladaptive outcomes. Specifically, performance-approach goals were related to effort, persistence, competitiveness, and high scores, whereas performance-avoidance goals were related to test anxiety, low self-efficacy, and low grades (Elliot \& McGregor, 2001).

All in all, it appears the quality of education has been reflected not only in the subjects taught and achievement levels reached, but also in the learning environment. The environment both mirrors and influences the behavior of students, and is affected by events within and outside of the school. Most educators and researchers have agreed that the total environment should be comfortable, pleasant, and

Anatolian Journal of Education, October $2019 \bullet$ Vol.4, No.2 
psychologically uplifting; should provide a physical setting that students find educationally stimulating; should produce a feeling of well-being among its occupants; and should support the academic process (Dinçol, Erdo, Oskay, Temel, \& Ylmaze, 2011).

Inspired by these views and acknowledging the scarcity of research in this area in Iran, the present study aimed to examine the relationship between a set of classroom management strategies that English as a foreign language (EFL) teachers apply in their classes and the students' perceptions of classroom activities and their goal orientations. In so doing, the following research questions were investigated:

1- Does EFL teachers' assertive classroom management play any significant role in the students' perceptions of classroom activities?

1.1-Does teachers' assertive classroom management play any significant role in the perception of interest?

1.2- Does EFL teachers' assertive classroom management play any significant role in the perception of joy?

1.3- Does EFL teachers' assertive classroom management play any significant role in the perception of choice?

1.4- Does EFL teachers' assertive classroom management play any significant role in the perception of challenge?

2- Does EFL teachers' assertive classroom management play any significant role in their students' achievement goal orientations?

2.1-DoesEFL teachers' assertive classroom management play any significant role in their students' mastery goals?

2.2- Does EFL teachers' assertive classroom management play any significant role in their students' performance goals?

2.3- Does EFL teachers' assertive classroom management play any significant role in their students' performance- avoidance goals?

3-How does EFL teachers' assertive classroom management influence on their students' perceptions of classroom activities and achievement goal orientations? (Qualitative section).

\section{METHOD}

\section{Participants}

The participants of the study comprised 147 EFL learners, male and female who were selected according to a convenience sampling among EFL students learning English in Language Institutes and students of university majoring at English teaching or translating and other majors. Given that the researchers were teaching in these institutes and universities, because of their convenient accessibility and proximity to the researchers, convenience sampling was utilized. The institutes were Hafez and Taranom e Bomdad, and Imam Reza University. All of them were in Mashhad. Some of the participants of present study were both teachers and students. Some of them were bachelor of art (BA) or master of art (MA) students. They were between 18 to 44 years old. Their language proficiency level was intermediate and upper-intermediate. 


\section{Instruments}

\section{Teacher assertive management scale}

To measure teacher assertive management strategies, we utilized a questionnaire developed by Shawer (2010), as the data collection tool. We employed the Persian version of the questionnaire translated by Aliakbari and Bozorgmanesh (2015) for the participants' understanding of the items. According to Aliakbari and Bozorgmanesh (2015), the instrument adequately assesses teachers' assertive management skills and its relevance and applicability have been substantiated in previous research. The applied questionnaire included scales referring to classroom management variables and their dimensions, that is, actions related to: organizing, teaching management, teacher-student. The questionnaire included four subsections that address components of classroom management: organization (8 items), teaching management (11 items), teacher-student relationship (10items), and teacher punish-reward strategies (8 items). relationship and teacher sanction/reward strategies.

A sample item for each factor is as follows:

Organization: The teacher comes to lectures on time.

$>$ Teaching management: The teacher provides challenging tasks for us to do.

$>$ Teacher- student relationship: The teacher uses the names of the students.

$>$ Teacher punishment-rewards: The teacher displays good work of students to the whole class.

Responses were shown on a five-point, Likert scale (from much to never: 1: Never, 2: Rarely, 3: Sometimes, 4: Often, 5: Always) to mark how well each item described their beliefs concerning their teachers' classroom management strategies. The process was not timed; however, participants normally completed it in approximately 10-12 minutes. High scores indicated a well-managed classroom, therefore more assertiveness in teachers' behavior, while low scores showed a less wellmanaged classroom and thus less assertiveness in teachers' manners. The validity and reliability of the translated questionnaire had been calculated through Cronbach's $\alpha$ which is (0.91).

\section{Students' perceptions of classroom environment}

To determine students' perceptions of classroom activities, the researchers used the translated version of 'Students Perceptions of Classroom Activities' scale designed and validated by Gentry and Gable (2001). It was translated to Persian and validated by Ghanizadeh and Jahedizadeh (2015). Validity evidence for construct interpretation was investigated through confirmatory factor analysis. A chisquare/ $d f$ ratio (2.38) and the RMSEA (.062) as well as the GFI (.78) were indicative of model fit. Furthermore, all items had accepted factor loadings. The Cronbach's alpha estimated for each perception ranged from .71 to .80 (interest $=.86$, challenge $=.73$, choice $=.71$, joy $=.79$ ).

The 'Students Perceptions of Classroom Activities' instrument contains 31 statements evaluating four dimensions (interest, challenge, choice, and joy). The scale measures the four dimensions via a 5point Likert-type response format (never, seldom, sometimes, often, and always). The participants were provided with directions on how to complete the scale. Sample items for each scale are as follows:

Interest: 1) What I do in my class fits my interests, and 2) I have an opportunity to work on things in my class that interest me.

$>$ Challenge: 1) I find the work in this class demanding, and 2) I am challenged to do my best in class.

Choice: 1) I can choose materials to work with in the class, and 2) I can choose an audience for my product.

$>$ Joy: 1) The activities I do in my class are enjoyable, and 2) I like the projects I work on in my class. 


\section{Achievement goal orientation inventory}

Students' goal orientation was measured by the translated version of Achievement Goal Orientation Inventory designed by Midgley, et al. (1998). The inventory made of three subscales, 6 items for each goal orientation and a total of 18 items, and it allowed responses ranging from 1 (not at all true of me) to 7 (very true of me). Table 1 represents three possible goal orientations as follows:

Table 1

Subscales of the AGOI along with the Corresponding Descriptions

\begin{tabular}{llc}
\hline Subscale & Definition & Alpha \\
\hline Mastery-approach & Attaining task-based or intrapersonal competence & .85 \\
Performance-approach & Attaining normative competence & .89 \\
Performance-avoidance & Avoiding normative incompetence & .74 \\
\hline
\end{tabular}

\section{Data Collection}

This study used a mixed- method design for gathering data. Therefore, data collection embraced distributing the three questionnaires among $147 \mathrm{EFL}$ learners (Quantitative section). The questionnaires were administered whenever possible during the year 2017. The titles of the three questionnaires were (1) Teacher's assertive management scale (2) Students' Perceptions of Classroom Environment questionnaire, and (3) Achievement Goal Orientation Inventory.

In addition, five students were selected to sit for an interview (Qualitative section) to explore their opinions on their teachers' assertive classroom management and the ways it would shape their perceptions of classroom activities and achievement goals.

\section{FINDINGS}

\section{Quantitative Phase}

Table 2 shows descriptive statistics of perceptions of classroom activities. Here, INT represents interest, CHA stands for challenge, CHO for choice, and Joy for enjoyment. According to the Table, CHA obtains the highest mean $(M=26.82, S D=4.03)$ followed by INT $(M=26.21, S D=5.74)$.

Table 2

Descriptive Statistics of Perceptions of Classroom Activities

\begin{tabular}{llllll}
\hline & $\mathrm{N}$ & Minimum & Maximum & Mean & Std. Deviation \\
\hline INT & 147 & 11.00 & 40.00 & 26.61 & 5.743 \\
JOY & 147 & 9.00 & 35.00 & 24.41 & 5.32 \\
CHA & 147 & 16.00 & 37.00 & 26.82 & 4.03 \\
CHO & 147 & 7.00 & 28.00 & 19.66 & 4.26 \\
Valid N (listwise) & 147 & & & & \\
\hline
\end{tabular}

Descriptive statistics of students' achievement goal orientations (mastery, performance, avoidance) are represented in Table 3. As the Table displays, mean score of mastery is 30.36, for performance, it is 34.91 , and for avoidance, it is 29.13 . 
Table 3

Descriptive Statistics of Student Goal Orientations

\begin{tabular}{llllll}
\hline & $\mathrm{N}$ & Minimum & Maximum & Mean & Std. Deviation \\
Mastery & 147 & 10.00 & 42.00 & 30.36 & 7.35 \\
Performance & 147 & 16.00 & 42.00 & 34.91 & 5.74 \\
Avoidance & 147 & 10.00 & 41.00 & 29.13 & 7.78 \\
Valid N (listwise) & 147 & & & & \\
\hline
\end{tabular}

Table 4 shows descriptive statistics of teachers' assertive classroom management strategies. In this Table, TOS stands for teacher organization strategies (8 items), TMS stands for teaching management strategies (11 items), TSRS for teacher-student relationship strategies (10 items), TPRS for teacher punishment and reward strategies ( 8 items), and TACMS for teacher assertive classroom management strategies. The mean score for teacher's assertive management is 128.17.

Table 4

Descriptive Statistics of Teacher Assertive Classroom Management

\begin{tabular}{llllll}
\hline & $\mathrm{N}$ & Minimum & Maximum & Mean & Std. Deviation \\
\hline TOS & 147 & 12.00 & 35.00 & 26.46 & 4.54 \\
TMS & 147 & 23.00 & 52.00 & 39.08 & 5.97 \\
TSRS & 147 & 18.00 & 46.00 & 35.97 & 5.44 \\
TPRS & 147 & 12.00 & 40.00 & 26.63 & 4.96 \\
TACMS & 147 & 76.00 & 165.00 & 128.17 & 16.13 \\
Valid N (listwise) & 147 & & & & \\
\hline
\end{tabular}

The reliability estimates of each variable computed via Cronbach's alpha are as follows: INT $(\alpha=.71)$, JOY $(\alpha=.69)$, CHA $(\alpha=.65)$, CHO $(\alpha=.63)$, Mastery $(\alpha=.70)$, Performance $(\alpha=.69)$, Avoidance $(\alpha=$ $.63)$, TACMS. $(\alpha=.73)$.

To examine the structural relations, the proposed model was tested using the LISREL 8.50 statistical package. In our proposed model, teacher assertive classroom management is considered as the independent variable the role of which on students' perceptions of classroom activities and goal orientations (as dependent variables) is estimated. A number of fit indices were examined to evaluate the model fit.

As demonstrated by Figure 1, the fit indices are slightly below those thresholds: GFI (.89) RMSEA (.89), NFI (.88), and the chi-square/df ratio (2.58). This implies that the model had a good fit with the empirical data. 


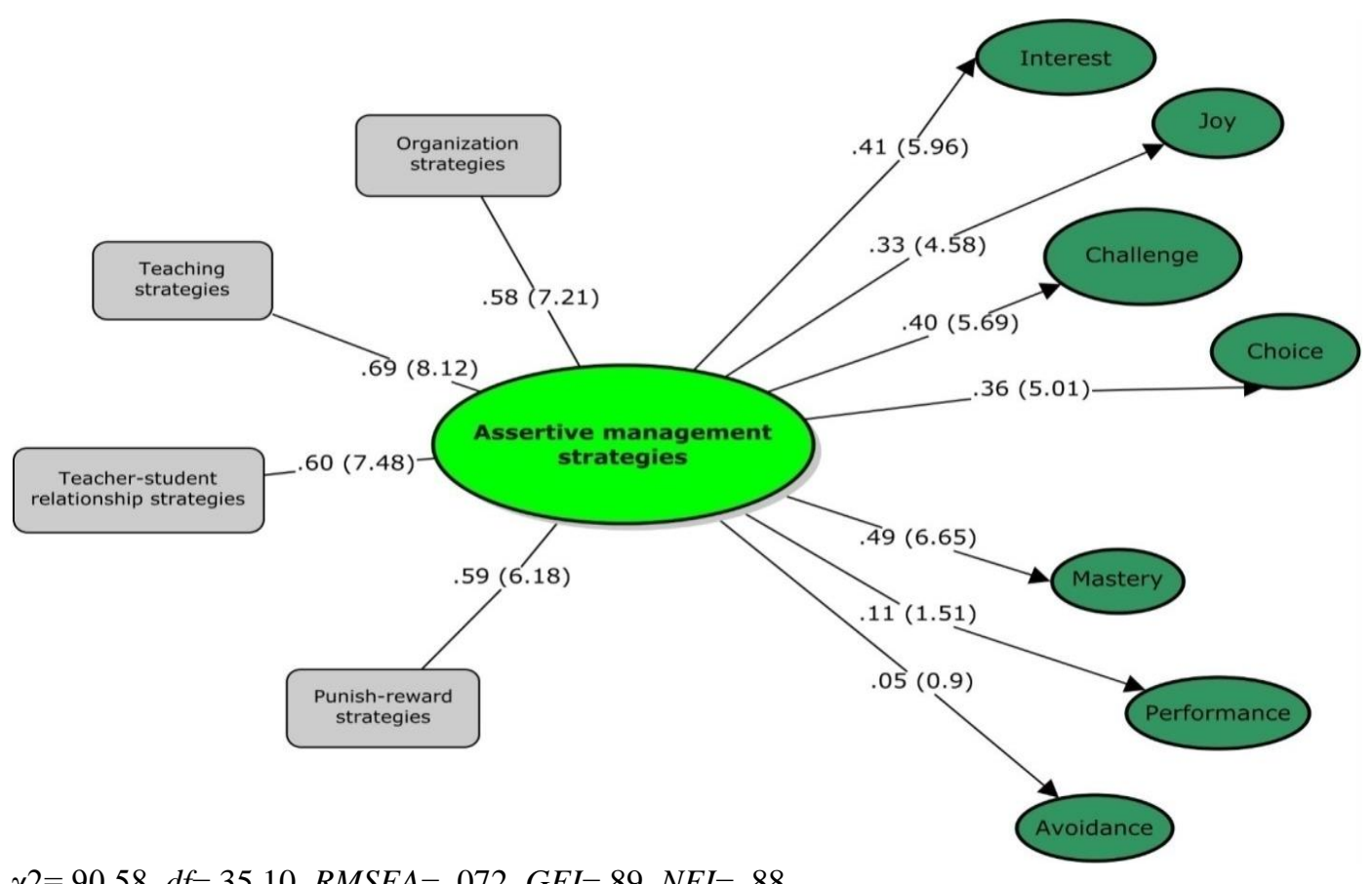

$\chi 2=90.58, d f=35.10, R M S E A=.072, G F I=.89, N F I=.88$

Figure 1

The Schematic Representation of the Relationships among the Variables in Questions

Note: For ease of presentation, observed variables are not included and only latent variables are presented.

To check the strengths of the causal relationships among the variables, the $t$-values and standardized estimates $(\beta)$ were examined. The results demonstrated that teacher assertive classroom management had positive significant impact on all perceptions: Interest $(\beta=.41, t=5.96)$, Joy $(\beta=.35, t=4.58)$, Challenge $(\beta=.40, t=5.69)$, and Choice $(\beta=.36, t=5.01)$. As can be seen, the highest impact is exerted on interest and challenge. Among the three achievement goals, only mastery goal is influenced by teacher assertive classroom management strategies $(\beta=.49, t=6.65)$.

The correlation coefficients between students' perceptions of classroom activities and teachers' assertive classroom management strategies are presented in Table 5. As can be seen, the highest correlation was observed between TACMS and INT: $(r=0.43, p<0.05)$, followed by TACMS and CHA ( $r=0.37, p<0.05)$. The lowest correlation is between TACMS and JOY $(r=0.32, p<0.05)$.

Table 5

The Correlation between Students' Perceptions of Classroom Activities and Teachers' Assertive Classroom Management

$\begin{array}{llllll} & 1 & 2 & 3 & 4 & 5 \\ \text { 1. INT } & 1.00 & & & & \\ \text { 2. JOY } & .85^{* *} & 1.00 & & & \\ \text { 3. CHA } & .54^{* *} & .51^{* *} & 1.00 & & \\ \text { 4. CHO } & .31^{* *} & .22^{* *} & .47^{* *} & 1.00 & \\ \text { 5. TACMS } & .43^{* *} & .32^{* *} & .37^{* *} & .36^{* *} & 1.00 \\ \text { **. Correlation is significant at the } 0.01 \text { level(2-tailed) } & & & \end{array}$


The relationship between students' goal-orientations and teacher's assertive classroom management is also calculated. The results are presented in Table 6 . As the table shows, among the achievement goalorientations, mastery is associated with TACMS significantly and positively, albeit moderately $(r=$ $0.40, p<0.05)$.

Table 6

The Correlation between Students' goal orientation and Teachers' Assertive Classroom Management

\begin{tabular}{lllll}
\hline & 1 & 2 & 3 & 4 \\
\hline 1. Mastery & 1.00 & & & \\
2. Performance & $.41^{* *}$ & 1.00 & & \\
3. Avoidance & .07 & $.32^{* *}$ & 1.00 & \\
5. TACMS & $.40^{* *}$ & $.19^{*}$ & .054 & 1.00 \\
**. Correlation is significant at the 0.01 level(2-tailed) & &
\end{tabular}

To check the associations among TACMS components together and with total TACMS, another correlation was run. The results are presented in Table 7. As stated earlier, TOS stands for teacher organization strategies ( 8 items), TMS stands for teaching management strategies (11 items), TSRS for teacher-student relationship strategies (10 items), TPRS for teacher punishment and reward strategies (8 items), and TACMS for teacher assertive classroom management strategies. Total TACMS has the highest correlation with TMS $(r=0.83, p<0.05)$.

Table 7

The Correlation between Students' Perceptions of Classroom Activities and Teachers' Assertive Classroom Management

\begin{tabular}{|c|c|c|c|c|c|}
\hline & 1 & 2 & 3 & 4 & 5 \\
\hline 1. TOS & 1.00 & & & & \\
\hline 2. TMS & $.50 * *$ & 1.00 & & & \\
\hline 3. TSRS & $.34 * *$ & $.48 * *$ & 1.00 & & \\
\hline 4. TPRS & $.36^{* *}$ & $.52 * *$ & $.51 * *$ & 1.00 & \\
\hline 5. TACMS & $.69 * *$ & $.83^{* *}$ & $.77 * *$ & $.77 * *$ & 1.00 \\
\hline
\end{tabular}

\section{Qualitative Phase}

\section{Results of interviews}

Qualitative content analysis was conducted in this study. The data including interviews were analyzed through reading, coding, and revising the codes. In this way, we hoped to answer the qualitative research question as follows.

How does EFL teachers' assertive classroom management influence on their students' perceptions of classroom activities and their achievement goal orientations?

Primarily, in the actual analysis, the researchers read transcripts repeatedly and highlighted the parts that appeared to be relevant. The researcher coded each part manually and identified recurrent codes. The researchers then went through the codes and identified recurrent patterns. Finally, the identified patterns were presented and discussed. During this process, quotations were made from the highlighted parts, and the researchers translated the quoted parts into English. It was tried to retain as much of the essence and intention of what the interviewees said as possible, rather than attempting a word for word translation.

In this section, the semi-structured individual interviews with five participants were administered faceto-face. Each interview lasted some 14 minutes. A topic list was used to structure the interview questions. These topics included the general attitudes toward assertive classroom management and a 
list of some questions related to sub factors of students' perceptions of classroom activities and goal orientations.

The interviewees were all females of two different related contexts (universities and institutes). Participants A, B, and C were from Imam Reza International University with MA degree in English teaching. A and B were at the same time, both teacher and student, they were teaching in institute and graduating in university as a MA student. Participant D was studying MA degree in English translating. Participant E was a student from institute with BA degree in Architecture. Their age range was from 24 to 44 . Thus, attempt was made to cover all demographics information such as age, level, and major. The requests of interview ring around the theme of attitudes toward assertive classroom management of the teacher and its roles on the students' perceptions of classroom activities and their goal orientations. The researcher aimed to bring their ideas on the sub heading of each variable.

In interviews, first the concept of the teachers' assertive classroom management was explained completely with the definitions of its four sub factors:

1-organization

2-teaching strategies

3-teacher-student relationship strategies

4-teacher's punishment reward strategies

Then, with regards to the teacher's classroom management strategies, some questions were asked from the interviewees. Some of them are as follows:

Questions asked from the teachers

1- Do you utilize positive reinforcement to motivate your students learn successfully? How would this affect them?

2- What do you do to have an attractive classroom atmosphere?

3- Are your rules and disciplines in class flexible?

Questions asked from the students

1-Do you prefer a teacher with strong and clear guidance of the lessons and class activities?

2-Does it affect you if you have a cheerful and high-spirited teacher? How?

3-What's your idea of having boring disciplined teacher?

Whilst the researchers were asking the above questions, they tried to figure out the answers to these two issues:

1- The effects of teacher's assertive classroom management on students' perceptions of classroom activities

2- The effects of teacher's assertive classroom management on students' goal orientations?

To answer the first question, four out of five participants agreed that the teacher's assertive classroom management positively affects their perceptions of classroom activities mostly on their challenge, joy, and interest respectively. For instance, Participant A answered:

If I consider myself, my teacher's assertive classroom management will challenge me in class, attracts my attention to the lesson. Also, I enjoy more and choose more things to learn. Furthermore, it gives 
me a sense of self confidence and also it makes me accept what my teacher explains and says. I will be encouraged to do more pre reading for the lesson of the next session.

Only, the participant E thought that it has no effect on her perceptions of classroom activities: She said: It just makes me sure that my course lessens are continuing appropriately and on time.

Regarding the answers of question number two, all of the participants agreed that the teacher's assertive classroom management reinforces mostly, mastery goal orientations in them and just two of them believed that it also encourages performance goal and performance-avoidance goal.

For example, participant B answered:

When my teacher knows his job well and manages the class effectively, I will be attracted unconsciously, and start studying and learning English with the aim of being perfect in it, and become like my teacher in English.

And in similar vein, participant D said:

When my teacher employs assertive classroom management, I like to learn more and better than before, and also want to perform better than others in the class and avoid getting a bad grade.

As seen, most of our participants had the same idea about the positive effect of the teachers' assertive classroom management on their perception of classroom activities with its most impact on challenge, interest, and joy. This is, to a large extent, in line with the results of the quantitative phase which showed that the teachers' assertive classroom management had positive significant impact on all perceptions: Interest $(\beta=.41, t=5.96)$, Joy $(\beta=.35, t=4.58)$, Challenge $(\beta=.40, t=5.69)$, and Choice $(\beta=.36, t=5.01)$. As can be seen, the highest impact is exerted on joy and challenge.

Regarding the answers to the second question, our analysis reveals that the teachers' assertive classroom management encourages their students' goal orientations, especially mastery goal. This is also in line with the results of the quantitative phase, as it showed that among the three achievement goals, only mastery goal was influenced by teacher assertive classroom management strategies $(\beta=.49$, $t=6.65$ ). In general, on the basis of the findings set out in the previous section, their opinions were in line with QUAN phase.

\section{DISCUSSION AND CONCLUSION}

The present study demonstrated that teachers' assertive classroom management played a significant role in their students' perceptions of classroom activities. An analysis of the past fifty years of educational research as noted by Wang, Haertel, and Walberg (1993) revealed that effective classroom management increases student engagement, decreases disruptive behaviors, and makes good use of instructional time. Most classroom management research today has been concerned with identifying how teachers bring about student engagement with each other and limit the disruptions.

According to Aliakbari and Bozorgmanesh (2015), Iranian high school teachers apply ample classroom management strategies. The reported findings indicate that these strategies (organizing, teaching management, teacher-student relationship, and teacher sanction-reward strategies) are partially applied by Iranian high school teachers with different degrees. Research findings converge on the conclusion that "teachers who approach classroom management as a process of establishing and maintaining effective learning environments tend to be more successful than teachers who place more emphasis on their as authority figures or disciplinarians" (Brophy, 1988, p.1).

In the present study, the results indicated that the mean score for total teacher's assertive management was 128.17. The mean score for teacher's managing strategies was 39.08 and 35.97 for teacher student relationship that were the highest mean scores respectively. This means that teachers in this sample 
used teaching management and teacher student relationship more than the two other components of classroom management. This is consistent with the results of the research done by Aliakbari and Bozorgmanesh (2015).

The nature of classes, teaching and students, make the classroom environment an important element of student success (Doyle, 2006). Teachers create both the psychological and social environments for learning (Martin, \& Sass, 2010). As a result, teachers who have more assertive management strategies and spend more time on preparation and effective teaching can inspire and encourage more positive perceptions among their students.

Positive perceptions towards classroom activities can in turn stimulate more learning-enhanced skills and strategies, such as, self-efficacy, self-regulation, and so on. For example, Ghanizadeh and Alishahi (2016) investigated the nexus between perceptions of classroom activities and self-regulation and reported that all four perceptions had significant positive correlations with self-regulation. The highest correlations were found between challenge and self-regulation followed by the correlation between choice and self-regulation.

According to their study, students' perceptions positively affect students' self-regulation skills and based on the results of the present study teachers' assertive classroom management had a positive impact on the students' perceptions of classroom activities. By juxtaposing the findings of these two studies, we can expect that a satisfactory teacher's assertive classroom management can also influence the student's self-regulatory skills positively.

In the present study, the relationship between students' goal-orientations and teacher's assertive classroom management was also examined. As the results showed, among the achievement goalorientations, mastery was associated with TACMS significantly and positively, albeit moderately $(r=$ $0.40, p<0.05)$.

A non-threatening learning environment develops a sense of belonging among students (Freeman, Anderman, \& Jensen, 2007), makes them self-initiated and self-confident (Rogers, et al., 2001), and thus increases their desire for learning. It is empirically evident that teachers' behavior, classroom activities they use, and the teaching methods they adopt can be sources of motivation for language learners (Oxford, 1998). Teachers can promote motivation in language learners by considering the goals of the learner (Allahdadi, Jahedizadeh, Ghanizadeh, \& Hosseini, 2016; Jahedizadeh, Allahdadi, \& Ghanizadeh, 2015; Jahedizadeh, Ghonsooly, Ghanizadeh, \& Akbari, 2015), specifically the protection from loss of self-confidence and the development of adaptive self-regulatory skills (Falout, Elwood, \& Hood, 2009).

Research demonstrated that teacher management styles maximize students' academic performance and keep them on task (Adeyemo, 2012; Altinel, 2006), engage students in learning (Everston \& Weinstein, 2006; Rahimi, \& Asadollahi, 2012), and influence their motivation and achievement (Freiberg, Stein, \& Huang, 1995). In this cycle, "the more that students perceive their teacher cares about them, the more the students will care about the class, and the more likely they will be to pay attention in class and consequently learn more course material" (Teven \& McCroskey, 1997, p. 167). This entails adopting learning-centered goals.

Researchers have investigated a number of important ways in which goal orientations relate to students' behaviors and attitudes in the classroom (Pintrich \& Schunk, 2002). For example, students endorsing mastery goals have been shown to be more intrinsically interested in learning, have a positive attitude towards learning, and enjoy challenging work (Ames \& Archer, 1988). A good classroom management by teacher will increase the student's motivation to learn and adapt mastery goals. When a teacher exerts good assertive classroom management strategies in class, it creates a 
sense of interest to English and learning English. This in turn stimulates motivation in students to learn; therefore, they start to put realistic goals for their studying

On the whole, the yielded findings of the present study lead to the conclusion that the EFL teachers' assertive classroom management strategies have a significant role in their students' perceptions of classroom activities and their achievement goal orientations in the context of Iran. The results confirmed significant positive relationship of teachers' assertive classroom management and students' perceptions of classroom activities, with all its components (interest, challenge, choice, and joy), mostly with interest and challenge. In other words, when an English teacher employs a good assertive classroom management in his/her class, this influences the students' perceptions and increases their interest in classroom activities, challenges them more, and increases their joy of class and class activities. The results also indicated that there was a positive significant relationship between teachers' assertive classroom management and mastery goal. This means if teacher exhibits assertive classroom management, the students tend to adapt mastery goal and they will be motivated to learn English in order to master it.

These findings can have important implications in teacher education domain, especially for in-service training programs for the Iranian EFL teachers to efficiently practice classroom management strategies. When a teacher implements the assertive classroom management strategies well, it will arouse their students' interest, and joy in class, also challenge them more, and finally it helps their students to attain their learning objectives, i.e., mastery goal. Teachers should guide learners toward mastery goal which leads to a noticeable augmentation in the level of learners' self-confidence and self-efficacy. Also, it helps teachers to be more self- confident and have qualified and effective classes.

A clear understanding of the effectiveness of classroom management as a package of instructional practices is necessary to establish teacher buy-in to implementing and sustaining classroom management. Identifying the most effective way to provide pre-service and in-service teachers with content and pedagogical () knowledge as well as providing a system to support fluctuations in teacher effectiveness is critical to elevate the context of classroom environments and the dedication of teachers to their profession (Oliver, et al., 2011).

\section{REFERENCES}

Adeyemo, S.A. (2012). The relationship between effective classroom management and academic achievement. European Journal of Educational Studies, 4(3), 100-120.

Aliakbari, M., \& Bozorgmanesh, B. (2015). Assertive classroom management strategies and students' performance: The case of EFL classroom. Cogent Education, 2, 101-199. http://dx.doi.org/10.1080/ 2331186X.2015.1012899.

Allahdadi, S., Jahedizadeh, S., Ghanizadeh, A., \& Hosseini, A. (2016). On the impact of achievement goal-orientations on EFL university students' demotivation. Int. J. of Edu. Inv, 3(1), 103-114.

Altinel, Z. (2006). Student misbehavior in EFL classes: Teachers and students' perspectives (Unpublished master thesis). Cukurova University, Adana, Turkey.

Ames, C., \& Archer, J. (1988). Achievement goals in the classroom: students' learning strategies and motivation processes. Journal of Educational Psychology, 80(3), 260-267.

Brophy, J. E. (2006). History of research in classroom management. In C. M. Evertson, \& C. S. Weinstein (Eds.), Handbook of classroom management: research, practice, and contemporary issues (pp. 17-43). Mahwah, NJ: Lawrence Erlbaum Associates, Inc. 
Doyle, W. (2006). Ecological approaches to classroom management. In C. M. Evertson, \& C. S. Weinstein (Eds.), Handbook for classroom management: Research, practice, and contemporary issues (pp. 97-125). London: Lawrence Erlbaum Associates

Elliot, A. J., \& Harackiewicz, J. M. (1996). Approach and avoidance achievement goals and intrinsic motivation: A mediational analysis. Journal of Personality and Social Psychology, 70(3), 461-475. http://dx.doi.org/10.1037/0022-3514.70.3.461.

Elliot, A. J., \& McGregor, H. A. (2001). A 2 X2 achievement goal framework. Journal of Personality and Social Psychology, 80, 501-519. http://dx.doi.org/10.1037/0022-3514.80.3.501.

Falout, J., Elwood, J., \& Hood, M. (2009). Demotivation: Affective states and learning outcomes. System, 37, 403-417.

Freiberg, H. J., Stein, T. A., \& Huang, S. (1995). Effects of a classroom management intervention on student achievement in inner-city elementary schools. Edu. Research and Evaluation, 1, 36-66.

Freeman, T., Anderman, L., \& Jensen, J. (2007). Sense of belonging in college freshman at the classroom and campus levels. Journal of Experimental Education, 75, 203-220.

Ghanizadeh, A., \& Alishahi, M. H. (2016). The bonds between efl learners' perceptions of classroom activities, self-regulatory skills, and language achievement. International Journal of Educational Investigations, 3(2), 72-85.

Ghanizadeh, A., \& Jahedizadeh, S. (2015). An exploration of EFL learners' perceptions of classroom activities and their achievement goal orientations. International Journal of Research Studies in Education, 4(3), 33-45.

Ghanizadeh, A., Jahedizadeh, S., \& Allahdadi, S. (2016). EFL learners' goal-orientation: A crosscontextual analysis. Journal of Global Research in Education and Social Science, 7(2), 108-114.

Jahedizadeh, S., Allahdadi, S., \& Ghanizadeh, A. (2015). Probing the role of demotivation in avoidance goal orientation among EFL learners at private language institutes. International Journal of Research Studies in Psychology, 5(2), 3-14.

Jahedizadeh, S., Ghonsooly, B., Ghanizadeh, A., \& Akbari, O. (2015). A cross-contextual analysis of EFL learners' perceptions of classroom activities. J. of App. Ling. and Lang. Res., 2(4), 322-336.

Martin, N. K., \& Sass, D. A. (2010). Construct validation of the behavior and instructional management scale. Teach. and Te. Edu., 26, 1124-1135. http://dx.doi.org/10.1016/j.tate.2009.12.001.

Midgley, C., Kaplan, A., Middleton, M., Maehr, M. L., Urdan, T., Anderman, L. H., Anderman, E., \& Roeser, R. (1998). The development and validation of scales assessing students' achievement goal orientations. Contemporary Educational Psychology, 23(2), 113-131.

Mucherah, W., \& Frazier, A. D. (2013). How teachers perceive their classroom environments and student goal orientation: A look into high school biology classrooms in Kenya. British Journal of Education, Society \& Behavioral Science, 3(1) 1-17.

Oliver, R. M., Wehby, J. H., Reschly, D. J. (2011). Teacher classroom management practices: effects on disruptive or aggressive student behavior. Campbell Systematic Reviews, 4(2), 8-10 
Oxford, R. L. (1998, March). The unravelling tapestry: Teacher and course characteristics associated with demotivation in the language classroom. Paper presented at the TESOL ' 98 Congress, Seattle.

Pintrich, P. R., \& Schunk, D. (2002). Motivation in education: Theory, research and Applications. Englewood Cliffs, NJ: Merrill Prentice Hall.

Rahimi, M., \& Asadollahi, F. (2012). EFL teachers' classroom management orientations: investigating the role of individual differences and contextual variables. Procedia-Social \& Behavioral Sciences, $31,43-48$

Roger, C. G., Galloway, D., Armstrong, D., \& Leo, E. (2001). Gender differences in motivational style. European Education, 32, 79-93.

Shawer, S. (2010). The influence of assertive classroom management strategy uses on student teacher pedagogical skills. Academic Leadership, 8(2), 1-20.

Teven, J., \& McCroskey, J. (1997). The relationship of perceived teacher caring with student learning and teacher evaluation. Communication Education, 46, 167-177.

Wang, M. C., Haertel, G. D., \& Walberg, H. J. (1993). What helps students learn? Educational Leadership 51(4), 74-79.

Wong, H. K., \& Rosemary, T. (2001). How to be an effective teacher: The first days of school. Mountain View, CA: Harry K. Wong Publications. 